Taiwan 921 Earthquake: A Pictorial Review

Henry $K$. Cheng

Emergency Department, Mackay Memorial Hospital, Taipei, Taiwan ROC

921 is the date that Taiwan suffered from a major earthquake for the first time since the last century. It resulted in multiple casualities and injuries. We had not been wellprepared in the past, and we have learned from this experience and will be prepared for future such events.

We will relate this unfortunate event using a pictorial review of the disaster from alive to dead, and from human casualities to environmental destruction. We will relate the difficulties encountered in rescue attempts and will share our experiences. We thank those international rescue teams who arrived in Taiwan, who gave their greatest efforts to help us to search for surviving victims and who shared their experiences with us.

Keywords: assistance; disaster; casualities; damage; earthquake; international; rescue; search; teams

E-mail: henryckh@email.com

\section{Lessons Learned from the Great Hanshin-Awaji}

Disaster

Yosbio Murayama, MD; Hirofumi Kosuga, MD

Department of Surgery, Akashi National Hospital, JAPAN

On 17 January 1995, a tremendous earthquake occurred just below the southern part of Hyogo Prefecture, Japan. The citizens of the stricken area, having enjoyed a safe and peaceful life for a long time, were caught off guard. Consequently, more than 6,000 people were killed and more than 50,000 people were injured. More than 310,000 people temporarily were left homeless.

Many lessons have been learned from this earthquake disaster. This earthquake made 1995 a turning point in disaster preparedness in Japan. Many people, organizations, national governmental agencies, and local governments have begun to consider preparedness and mitigation for future disasters.

Keywords: disaster; earthquake; Kobe; lessons; response E-mail: murayama@ma.neweb.ne.jp 